\title{
Binaural detection as a function of signal frequency and noise level
}

\author{
W. A. WILBANKS \\ University of Georgia, Athens, Georgia 30602
}

\begin{abstract}
This is a continuation of work by a number of investigators on the dependency of binaural masking-level differences (MLDs) upon signal frequency and noise spectrum level. Monaural (SM) and binaural $(\mathrm{S} \pi)$ signals of $150,250,500$, and $1,200 \mathrm{~Hz}$ were employed. The spectrum level of correlated noise (NO) was varied between +10 and $+55 \mathrm{~dB}$. The results show that, with very low noise levels $(+10 \mathrm{~dB})$, the largest MLDs for monaural and binaural signals are obtained at $500 \mathrm{~Hz} \mathrm{(4}$ and $9 \mathrm{~dB}$, respectively). As the noise level is raised to $+55 \mathrm{~dB}$, the signal frequency at which the largest MLDs occur shifts to $250 \mathrm{~Hz}(12$ and $18 \mathrm{~dB})$. At $150 \mathrm{~Hz}$, the MLD increases from less than 1 and $3 \mathrm{~dB}$ to about 10 and $17 \mathrm{~dB}$ as the noise level is increased from +10 to $+55 \mathrm{~dB}$. At $1,200 \mathrm{~Hz}$, the MLD is relatively independent of noise level. Data are presented to support the argument that the small MLDs found with low-frequency signals at low noise levels are a special case of the effects upon detection of reducing the correlation of the masker due to the presence of uncorrelated acoustic noise generated under earphones and internal auditory system noise.
\end{abstract}

Hirsh (1948) and Licklider (1948) published the "classic" studies on what has come to be termed binaural unmasking. Since then, programs of research on binaural detection have been vigorously pursued by many investigators in many laboratories. A number of the basic facts of binaural detection have been clearly established, and exciting theories or models have been proposed to account for and to integrate these facts (Durlach, 1972; Hafter, 1971; Jeffress, 1972; Jeffress, Blodgett, Sandel, \& Wood, 1956; Osman, 1971, 1973). Under optimal conditions, when a signal and a noise are presented to both ears and one or the other is reversed in phase, the signal can be detected at a level on the order of $18 \mathrm{~dB}$ lower than when both are in phase (Blodgett, Jeffress, \& Taylor, 1958; Jeffress, Blodgett, \& Deatherage, 1952, 1962; Jeffress, et al., 1956; Webster, 1951). Also, the detection of a tonal signal at one ear, partially masked by a noise at that ear, can be improved by as much as $10 \mathrm{~dB}$ when identical noise is added at the other ear (Blodgett, Jeffress, \& Whitworth, 1962; Mulligan \& Wilbanks, 1965; Weston \& Miller, 1965; Wilbanks \& Whitmore, 1968). In both cases, the signal to which the observer responds is too weak to be detected by monaural means. The literature on binaural unmasking is imposing, and excellent summaries have been provided by Durlach (1972) and Jeffress (1972).

In addition to the effects of reversing the phase of the signal or of the noise, Langford and Jeffress (1964),

This research was supported in part by grants from the National Science Foundation. Some of the results of this study were presented at the 79 th meeting of the Acoustical Society of America. Requests for reprints should be sent to W. A. Wilbanks, Department of Psychology, University of Georgia, Athens, Georgia 30602.
Licklider (1948), and Robinson and Jeffress (1963) have shown that the magnitude of the interaural correlation for the masking noise is a dominant variable affecting binaural unmasking when either speech or tonal signals are presented to both ears, that is, the reduction in masking that occurs when the signal is detected by the binaural hearing mechanism. This increase in signal detectability is termed the binaural masking-level difference, or MLD. Wilbanks and Whitemore (1968) extended this work on binaural unmasking and noise correlation to a wide range of signal frequencies in which the tonal signal is presented monaurally rather than binaurally. All of these studies have clearly shown that, as the correlation of the masking noise is reduced from unity, the size of the binaural advantage for detection (MLD) diminishes.

In their study, Wilbanks and Whitmore (1968) used tonal signals between 150 and $4,000 \mathrm{~Hz}$. The signals were partially masked by both narrow-band and wide-band noise at a spectrum level of $+33 \mathrm{~dB}$. Their results show that the magnitude of the binaural advantage for detection depends upon the frequency of the signal, as well as upon the interaural correlation for the noise. With correlated noise (NO), signal frequencies of $225,250,500$, and $1,200 \mathrm{~Hz}$ are superior to the purely monaural condition (NM-SM), that is, noise and signal presented to only one ear, by roughly $6,10,8$, and $5 \mathrm{~dB}$, respectively. Above $2,000 \mathrm{~Hz}$, binaural signal detection has little advantage over monaural. At $200 \mathrm{~Hz}$, the maximal difference between binaural and monaural listening is about $3 \mathrm{~dB}$. The difference at $150 \mathrm{~Hz}$ is negligible. Why does the addition of correlated noise at the nonsignal ear have virtually no effect on detection at $150 \mathrm{~Hz}$ and such a small effect at $200 \mathrm{~Hz}$ ?

In addition to studying interaural phase relations for 
various signal frequencies with intense maskers, Hirsh (1948) also investigated the effects of noise spectrum level on the binaural masked threshold at $200 \mathrm{~Hz}$. His data show clearly that the amount of binaural unmasking (MLD) depends upon the level of the masker. Canahl and Small (1965), Dolan (1968), Dolan and Robinson (1967), McFadden (1968), and Wilbanks and Cummins (Note 1) have all confirmed Hirsh's finding that the size of the MLD at low frequencies is critically dependent upon the spectrum level of the noise. These results suggest that the failure of Wilbanks and Whitmore (1968) to obtain a sizable MLD at $150 \mathrm{~Hz}$ was due to the low masker level they employed.

The present study provides additional data relating binaural detection to noise level over a wide range of signal frequencies.

\section{METHOD}

Tonal signals of $150,250,500$, and $1,200 \mathrm{~Hz}$ were presented monaurally (SM) to the observer's more sensitive ear and binaurally with the signal reversed in phase at one ear relative to the other $(\mathrm{S} \pi)$. The duration of the signal $(150 \mathrm{msec})$ was controlled by an Iconix 6255 electronic counter that triggered a GrasonStadler 829D switch, gating the signals with a 10-msec on-off time. The length of the signal was measured across the subject's earphones (TDH-49) with a Ballantine true-rms voltmeter.

Each signal from 250 through $1,200 \mathrm{~Hz}$ was partially masked by continuous wide-band noise $(50-5,000 \mathrm{~Hz})$. A continuous $250-\mathrm{Hz}$ narrow-band noise centered at $150 \mathrm{~Hz}$ was used to mask the $150-\mathrm{Hz}$ signal due to a nonlinearity in the spectrum of the wide-band masker below $250 \mathrm{~Hz}$. The interaural correlation of the noise was +1.00 (NO). The noise was presented at spectrum levels of $+10,+25,+40,+49$, and $+55 \mathrm{~dB}$ re .0002 microbar. The spectrum level of the noise was measured at the signal frequency with a Hewlett-Packard 302A wave analyzer. Detection was also studied with both signal and noise presented monaurally (NM-SM). This constituted the reference condition for determining MLDs, that is, the difference between detection under NM-SM and the two binaural conditions (NO-S $\pi$ and NO-SM).

The detectability of the signal was determined by means of the two-alternative forced-choice method (2AFC). The signal was programmed to occur at random in one or the other of two temporal intervals, marked for the observer by lights. The observers were informed that the a priori probability of the signal occurring during the first interval was .50 . The sequence of events within each forced-choice trial was (1) beginning (warning light), .1 sec; (2) pause, .8 sec; (3) first observation interval, $.15 \mathrm{sec}$; (4) pause, $.8 \mathrm{sec} ;(5)$ second observation interval, $.15 \mathrm{sec}$; and (6) response period, $2.0 \mathrm{sec}$.

Five subjects were used. Since all had had considerable experience with the $2 \mathrm{AFC}$ task, no special instructions were required, and no system of trial-by-trial informational feedback was used. The observers were sufficiently trained that no correction for response bias was required. All listening was done in standard IAC booths.

For each experimental condition, five signal levels, separated by $1-d B$ steps, were used. A minimum of 500 forced-choice trials were given to each observer at each signal level. From these data, psychometric functions were obtained relating percentage of correct choices to signal level. From these psychometric functions, the main dependent variable was determined: the signal level in decibels for $85 \%$ correct choices. Although the individual functions obtained were variable, the average psychometric functions yielded values of MLDs that were independent of the particular level of performance chosen for the determination of that MLD (85\% correct). The effect of changing the interaural condition was to displace the psychometric function from the NM-SM reference condition by an amount equal to the MLD (Egan, 1965; Egan, Lindner, \& McFadden, 1969).

\section{RESULTS}

The results for NO-S $\pi$ and NO-SM are presented as a series of curves in in Figures 1 and 2 and in Table 1. In Figures 1 and 2, the ordinate is the MLD in decibels re the average monotic condition (NM-SM), the abscissa is the frequency of the signal, and the parameter is the spectrum level of the masking noise. Examination of these functions shows clearly that the advantage of binaural over monaural detection depends upon both the frequency of the signal and the spectrum level of the masker. Table 1 presents averaged MLDs for each condition re NM-SM.

The results may be briefly summarized as follows. (1) Detection with NO-S $\pi$ is superior to NO-SM under all conditions. (2) The largest MLDs, which occur at $250 \mathrm{~Hz}$ with the $+55-\mathrm{dB}$ noise, are about $18 \mathrm{~dB}$ for NO-S $\pi$ and $12 \mathrm{~dB}$ for NO-SM. (3) With very low noise levels $(+10 \mathrm{~dB})$, the largest MLDs for monaural and binaural signals are obtained at $500 \mathrm{~Hz}(4$ and $9 \mathrm{~dB}$, respectively). (4) The effect upon detection of reducing the spectrum level of the masker is greatest with the $150-\mathrm{Hz}$ signal. The size of the MLD diminishes from about $17 \mathrm{~dB}$ to $3 \mathrm{~dB}$ for NO-S $\pi$, and from about $10 \mathrm{~dB}$ to less than $1 \mathrm{~dB}$ for NO-SM as the level of the masker is reduced from +55 to $+10 \mathrm{~dB}$. (5) For NO-S $\pi$, the difference

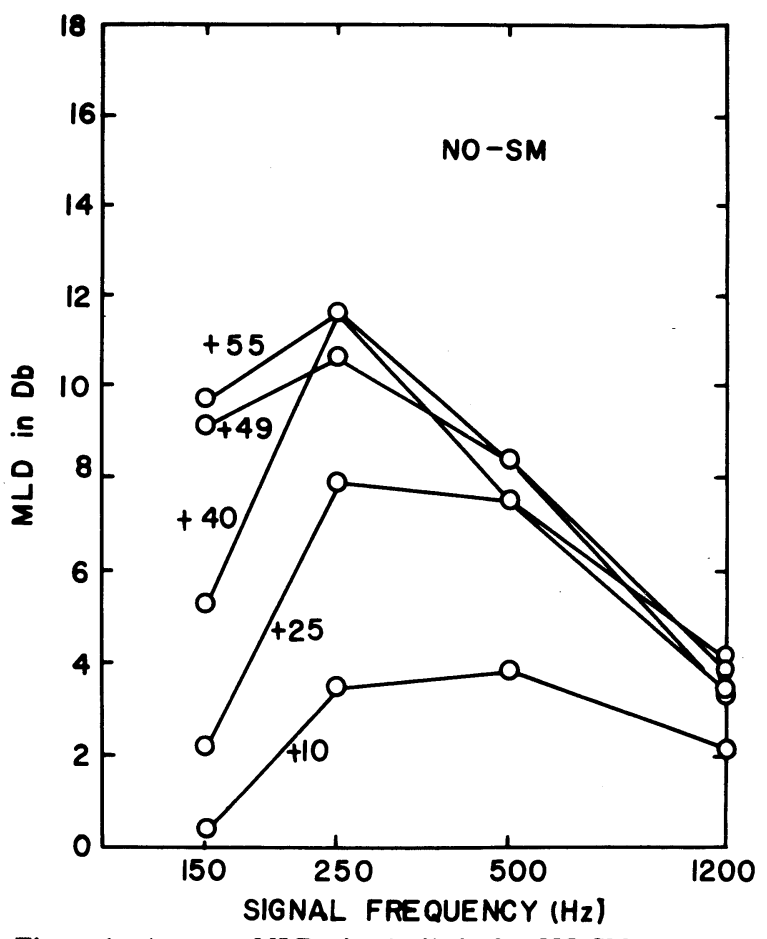

Figure 1. Average MLDs in decibels for NO-SM re NM-SM as a function of signal frequency. The parameter is noise spectrum level in decibels. 


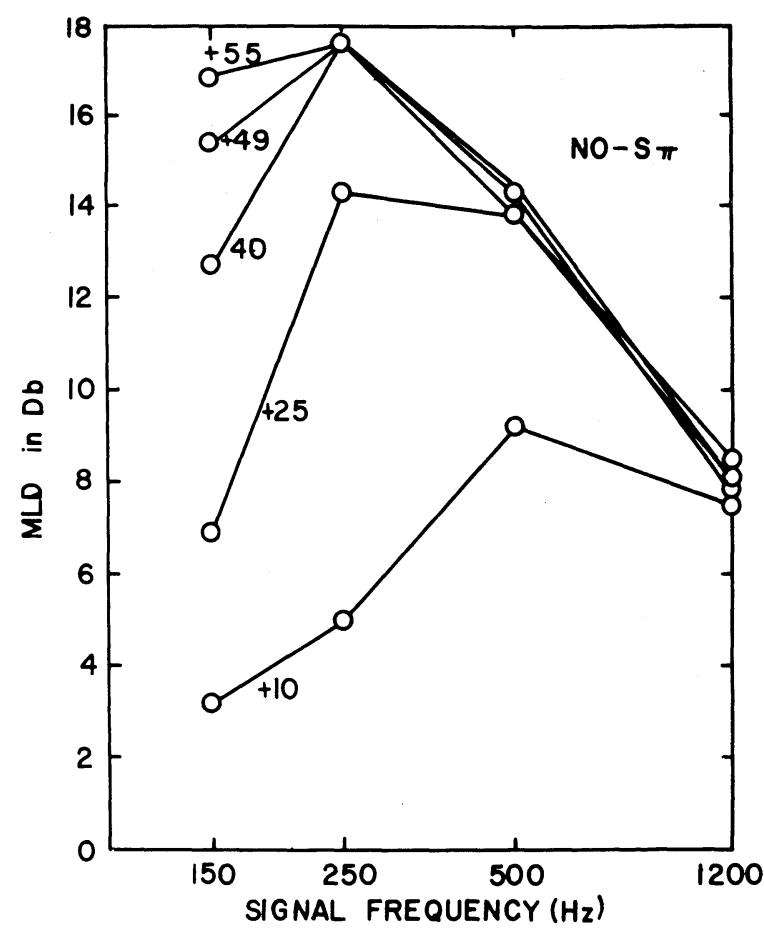

Figure 2. Average MLDs in decibels for NO-S $\pi$ re NM-SM as a function of signal frequency. The parameter is noise spectrum level in decibels.

between detection at 150 and $250 \mathrm{~Hz}$ is only about $1 \mathrm{~dB}$ with the +55- $\mathrm{dB}$ noise. At this level, the MLD at $150 \mathrm{~Hz}$ is larger than that at 500 and $1,200 \mathrm{~Hz}$ by about 3 and $9 \mathrm{~dB}$, respectively. (6) For NO-SM, the difference between detection at 150 and $250 \mathrm{~Hz}$ is only about $2 \mathrm{~dB}$ with the $+55-\mathrm{dB}$ noise. At this level, the MLD at $150 \mathrm{~Hz}$ is larger than that at 500 and $1,200 \mathrm{~Hz}$ by about 1 and $6 \mathrm{~dB}$, respectively. (7) Reduction in noise level has little effect upon detection at $1,200 \mathrm{~Hz}$, and it degrades detection at $500 \mathrm{~Hz}$ by about $4-5 \mathrm{~dB}$ when the noise level is reduced to $+10 \mathrm{~dB}$ for both NO-S $\pi$ and NO-SM.

In short, for a low-frequency signal $(150 \mathrm{~Hz})$, the amount of binaural unmasking is critically dependent upon the spectrum level of the noise. At 250, 500, and $1,200 \mathrm{~Hz}$, the size of the MLD is dependent upon the level of the masker only at low noise levels $(+10$ and $+25 \mathrm{~dB})$.

\section{DISCUSSION}

The results of the present study show that sizable MLDs can be obtained with low-frequency signals, provided that sufficiently high noise levels are used. Dolan (1968), Dolan and Robinson (1967), McFadden (1968), and Wilbanks and Whitmore have suggested that the explanation for the dependency of the MLD upon noise level at low frequencies may lie in part in the fact that a considerable amount of low-frequency acoustic noise is produced in the ear canal by such physiological actions as breathing, heart beat, muscle tonus, and the like. The soundpressure level of noise generated under earphones in this fashion has been measured by Anderson and Whittle (1971), Shaw and Piercy (1962), Sonderquist and Lindsey (1972), and Wilbanks and Cornelius (Note 2). The data of Shaw and Piercy indicate that the spectrum level of such acoustic body noise is about $+8 \mathrm{~dB}$ at $250 \mathrm{~Hz}$ and about $+25 \mathrm{~dB}$ at $150 \mathrm{~Hz}$. Obviously, this "body noise" will physically add to the noise generated by the earphones and will therefore affect detection. Since it would appear that the correlation over time of this noise is close to zero, the failure of Wilbanks and Whitmore to obtain a sizable MLD at $150 \mathrm{~Hz}$ would be due to the fact that the noise they employed for their NO condition actually had a correlation less than unity. The same would be true for the present study. In short, the reduction in the size of the MLD at low frequencies resulting from a reduction of the level of external masking noise reflects a lowering of the correlation of the noise. In such a case, the reduction in the size of the MLD would be predicted, given the fact that the MLD is known to depend upon the correlation of the masker. Using the data of Shaw and Piercy, Wilbanks and Whitmore estimated that the correlation of the noise they employed at $150 \mathrm{~Hz}$ was, in fact, only about +.86 . In a study in progress, Wilbanks and Cornelius (Note 2) placed probe microphones under MX41AR cushions (supra-aural) mounted in a spring-type headband and measured the interaural correlation of the noise in the ear canal when a $135-\mathrm{Hz}$ noise centered at $150 \mathrm{~Hz}$ was presented via TDH-49 earphones. The output of a single noise generator was used to drive both earphones, presumably giving a noise with a correlation of +1.00 as measured at the inputs to the phones (NO). Preliminary results indicate that, as the spectrum level of the input noise is reduced from +55 to $+10 \mathrm{~dB}$, the value of the correlation of the noise in the ear canal decreases from an average value of about +.85 to +.60 . The value of the interaural correlation of this meatal noise drops rapidly between external noise levels of +55 and $+40 \mathrm{~dB}$ and more slowly between +40 and $+10 \mathrm{~dB}$. The results so far confirm the notion that the effective correlation of the masker is reduced as the level of earphone-delivered noise is reduced. It seems clear that "body noise" does have a "decorrelating" effect, but this may not tell the whole story.

In addition to body noise at low frequencies, Jeffress (Note 3) has argued that the presence of some additional "internal noise" in the auditory system, probably of neural origin, must be assumed. Since the ears are not perfect transducers, pairs of impulses arising from corresponding parts of

Table 1

Average MLD in Decibels re NM-SM

\begin{tabular}{|c|c|c|c|c|c|c|c|c|}
\hline \multirow{2}{*}{$\begin{array}{l}\text { Noise Level } \\
\text { (in Decibels) }\end{array}$} & \multicolumn{4}{|c|}{ NO-S $\pi$ (in Hertz) } & \multicolumn{4}{|c|}{ NO-SM (in Hertz) } \\
\hline & 150 & 250 & 500 & 1200 & 150 & 250 & 500 & 1200 \\
\hline 55 & 17.0 & 17.8 & 14.2 & 8.2 & 9.8 & 11.5 & 8.5 & 4.0 \\
\hline 49 & 15.5 & 17.8 & 14.1 & 8.0 & 9.0 & 10.5 & 8.5 & 3.8 \\
\hline 40 & 12.8 & 17.8 & 14.1 & 8.0 & 7.2 & 11.5 & 7.8 & 4.0 \\
\hline 25 & 7.0 & 14.2 & 13.9 & 7.9 & 2.2 & 8.0 & 7.8 & 3.5 \\
\hline 10 & 3.0 & 5.0 & 9.2 & 7.8 & .3 & 3.7 & 4.0 & 2.1 \\
\hline
\end{tabular}


the waveform of NO at the two ears will not arrive simultaneously at the binaural center. Instead, impulses will be generated a little earlier or a little later in the cycle at one ear than at the other, the result being a fluctuation in the interaural correlation for the noise. We can think of this fluctuation as being a new kind of "noise," as being, possibly, "internal noise" that helps mask the signal. Diercks and Jeffress (1962) suggest that difference in the absolute threshold for tone as a function of its interaural phase are due, in part, to this "internal noise." Dolan and Robinson (1967) and McFadden (1968) have employed this notion to help explain binaural masking phenomena that occur when the intensity of the masker is varied. Durlach (1972) and Osman $(1971,1973)$ also employ in their models some sort of internal noise that effectively "decorrelates" the external masker. Durlach argues that the level of internally generated noise depends in a complex fashion on the level of the masking noise. Osman, Tzuo, and Tzuo (1975) have shown that a correlation model can quite accurately account for the results of Wilbanks and Whitmore (1968) that show how MLD varies as a function of signal frequency and noise correlation with an external +33-dB noise, provided that some sort of internal system noise is also assumed to reduce the correlation of the effective masker. Osman argues that the values of the internal noise parameters involved in his model are a complex function of frequency. It will be exciting to see how Osman's correlation model can deal with the present data, which show the dependency of MLD upon signal frequency and noise level.

To summarize, the size of the MLD depends upon signal frequency and the spectrum level of the masker. It appears that the small MLDs found with low-frequency signals at low noise levels are a special case of the effects upon detection of reducing the correlation of the masker. It would appear that both acoustic noise generated under earphones and internal system noise are involved.

\section{REFERENCE NOTES}

1. Wilbanks, W. A., \& Cummins, M. J. Unpublished data, 1966.

2. Wilbanks, W. A., \& Cornelius, P. T. Unpublished data, 1976.

3. Jeffress, L. A. Masking and binaural phenomena (Report 245). Austin, Tex: University of Texas Defense Research Laboratory, 1965.

\section{REFERENCES}

Anderson, C. M. B., \& Whittle, L. S. Physiological noise and the missing $6 \mathrm{~dB}$. Acustica, 1971, 24, 261-272.

Blodget, H. C., Jeffress, L. A., \& TAylor, R. W. Relation of masked thresholds to signal duration of various interaural phase-combinations. American Journal of Psychology, 1958, 71, 283-290.

Blodgett, H. C., Jeffress, L. A., \& Whitworth, R. H. Effect of noise at one ear on the masked threshold for tone at the other. Journal of the Acoustical Society of America, 1962, 34, 979-981.

Canahl, J. A., \& Small, A. M. Masking-level differences as a function of masker level. Journal of the Acoustical Society of America, 1965, 38, 928.

Diercks, K. J., \& Jefrress, L. A. Interaural phase and the absolute threshold for tone. Journal of the Acoustical Society of America, 1962, 34, 981-984.

Dolan, T. R. Effect of masker spectrum level on masking-level differences at low signal frequencies. Journal of the Acoustical Society of America, 1968, 44, 1507-1512.

Dolan, T. R., \& Robinson, D. E. Explanation of masking-level differences that result from interaural intensive disparities of noise. Journal of the Acoustical Society of America, 1967, 42, 977-981.

Durlach, N. I. Binaural signal detection: Equalization and cancellation theory. In J. V. Tobias (Ed.), Foundations of modern auditory theory (Vol. 2). New York: Academic Press, 1972.

EgAN, J. P. Masking-level differences as a function of interaural disparities in intensity of signal and noise. Journal of the Acoustical Society of America, 1965, 38, 1043-1049.

Egan, J. P., Lindner, W. A., \& McFadden, D. Masking-level differences and the form of the psychometric function. Perception \& Psychophysics, 1969, 6, 209-215.

HAFTE R, E. R. Quantitative evaluation of a lateralization model of masking-level differences. Journal of the Acoustical Society of America, 1971, 50, 1116-1122.

Hirsh, I. J. The influence of interaural phase on interaural summation and inhibition. Journal of the Acoustical Society of America, 1948, 20, 536-544.

JefFress, L. A. Binaural signal detection: Vector theory. In J. V. Tobia (Ed.), Foundations of modern auditory theory (Vol. 2). New York: Academic Press, 1972.

Jeffress, L. A., Blodgett, H. C., \& Deatherage, B. H. The masking of tones by white noise as a function of the interaural phases of both components. I. 500 cycles. Journal of the Acoustical Society of America, 1952, 24, 523-527.

Jeffress, L. A., Blodgett, H. C., \& Deatherage, B. H. Masking and interaural phase. II. 167 cycles. Journal of the Acoustical Society of America, 1962, 34, 1124-1126.

Jefrress, L. A., BlodgetT, H. C., SANdel, T. T., \& Wood, C. L. III. Masking of tonal signals. Journal of the Acoustical Society of America, 1956, 28, 416-426.

LANGFord, T. L., \& Jeffress, L. A. Effect of noise crosscorrelation on binaural signal detection. Journal of the Acoustical Society of America, 1964, 36, 1455-1458.

LiCKLide R, J. C. R. The influence of interaural phase relations upon the masking of speech by white noise. Journal of the Acoustical Society of America, 1948, 20, 150-519.

McFAdDEN, D. Masking-level differences determined with and without interaural disparities in masker intensity. Journal of the Acoustical Society of America, 1968, 44, 212-223.

Mulligan, B. E., \& Wilbanks, W. A. Effect of noise at one ear upon the detection of signals at the other ear. Journal of the Acoustical Society of America, 1965, 37, 1179.

Osman, E. A correlation model of binaural masking level differences. Journal of the Acoustical Society of America, 1971, 50, 1494-1511.

Osman, E. Correlation model of binaural detection: Interaural amplitude and phase variation for signal. Journal of the Acoustical Society of America, 1973, 54, 386-389.

Osman, E., Tzuo, H., \& Tzuo, P. L. Theoretical analysis of detection of monaural signals as a function of interaural noise correlation and signal frequency. Journal of the Acoustical Society of America, 1975, 57, 939-942.

Robinson, D. E., \& Jeffress, L. A. Effect of varying the interaural noise correlation on the detectability of tonal signals. Journal of the Acoustical Society of America, 1963, 35, 1947. 1952.

Shaw, E. A. G., \& Piercy, J. E. Physiological noise in relation to audiometry. Journal of the Acoustical Society of America, $1962,34,754$.

Sonderquist, D. R., \& Lindsey, J. W. Physiological noise as a masker of low frequencies: The cardiac cycle. Journal of the Acoustical Society of America, 1972, 52, 1216-1220.

WEBSTER, F. A. The influence of interaural phase on masked thresholds. I. The role of interaural time-deviation. Journal of the Acoustical Society of America, 1951, 23, 452-462.

Weston, P. B., \& Miller, J. D. Use of noise to eliminate one ear from masking experiments. Journal of the Acoustical Society of America, 1965, 37, 638-646.

Wilbanks, W. A., \& Whitmore, J. K. Detection of monaural signals as a function of interaural noise correlation and signal frequency. Journal of the Acoustical Society of America, $1968,43,785-797$.

(Received for publication October 22, 1979.) 